\title{
PERFIL SENSORIAL DE QUEIJO DE COALHO FABRICADO COM ÁCIDO LÁTICO
}

\section{Sensory profile of Coalho type cheese made with lactic acid}

\author{
Renata Golin Bueno Costa ${ }^{1}$, Gisela de Magalhães Machado Moreira ${ }^{1}$, Luiz Carlos \\ Gonçalves Costa Júnior ${ }^{l}$, Junio César Jacinto de Paula ${ }^{l}$, Denise Sobral ${ }^{1}$, \\ Fernando Antônio Resplande Magalhães ${ }^{1}$, Bruno Moreira de Souza ${ }^{2}$
}

\section{RESUMO}

O queijo de Coalho é o mais tradicional e um dos mais difundidos e fabricados na região Nordeste do Brasil, porém vem se tornando mais popular em outras regiões do país. O objetivo principal desse trabalho foi avaliar os aspectos sensoriais do queijo de Coalho em cinco tempos de estocagem refrigerada: 8, 15, 30, 60 e 90 dias. Foram avaliadas três tecnologias de produção de queijo de Coalho: por acidificação direta (com adição de ácido lático), com utilização de fermento mesofílico aromático (sem adição de ácido) e o queijo sem adição de ácido lático e de fermento. Pelo método de Análise Descritiva Quantitativa (ADQ) 10 provadores treinados avaliaram os seguintes descritores: aspecto global, cor externa, odor característico, resistência ao derretimento, textura, ranger ao mastigar, gosto ácido, gosto salgado e sabor. Não houve diferença entre os tratamentos para os atributos avaliados, com exceção do atributo textura. O tempo de estocagem foi fundamental nas análises realizadas, portanto sugere-se que o queijo de Coalho seja consumido o mais rápido possível para manter suas características típicas.

Palavras-chave: laticínios; derretimento; sabor.

\begin{abstract}
Coalho type cheese is the most traditional and one of the most manufactured in northeastern of Brazil but is becoming more popular in other parts of the country.

1 Empresa de Pesquisa Agropecuária de Minas Gerais, Instituto de Laticínios Cândido Tostes, Rua Tenente Luiz de Freitas, 116, Santa Terezinha, 36045-560, Juiz de Fora, MG, Brasil. E-mail: renata.costa@epamig.br

2 Universidade Federal de Juiz de Fora, Mestrado Profissional em Ciência e Tecnologia de Leite e Derivados, Juiz de Fora, MG, Brasil.

*Autor para correspondência
\end{abstract}

Recebido / Received: 26/07/2019

Aprovado / Approved: 28/12/2019 
The main objective of this study was to evaluate the sensory aspects of this cheese in five periods of storage: $8,15,30,60$, and 90 days. Three technologies for producing Coalho type cheese were evaluated: by direct acidification (with the addition of lactic acid), using mesophilic aromatic culture (without acid) and cheese without the addition of lactic acid and culture. The Quantitative Descriptive Analysis, with 10 trained tasters, was used to evaluate the following product descriptors: overall appearance, exterior color, aroma, melting resistance, texture, squeak while chewing, salty taste, acid taste, and flavor. There was no difference among treatments for the attributes evaluated, except for the texture. The time of storage was critical in the analysis, therefore it is suggested that the Coalho type cheese must be consumed as fast as possible to maintain their typical features.

Keywords: dairy products; melting; taste.

\section{INTRODUÇÃO}

O queijo de Coalho é um produto normalmente consumido após sofrer aquecimento, sendo frito ou assado (BEZERRA et al., 2016); dificilmente é consumido imediatamente após sua retirada do ambiente refrigerado por apresentar um sabor pouco pronunciado. Desta forma, espera-se que o queijo de Coalho frito ou assado apresente casca escurecida devido ao calor e também que as arestas permaneçam definidas, sem derretimento. Essas são tidas como as principais características tecnológicas do queijo de Coalho, além da típica sensação de ranger ao mastigar.

$\mathrm{O}$ escurecimento da casca do queijo mediante aquecimento se dá devido à reação de escurecimento não enzimático, conhecida como reação de Maillard. Esta reação é induzida pelo calor e ocorre entre glicídios redutores e o grupo amino de aminoácidos, peptídeos ou proteínas, resultando em produtos de cor escura conhecidos como melanoidinas (TAMANNA; MAHMOOD, 2015). Os principais fatores que influenciam neste tipo de escurecimento em queijos são: a) o tipo de Coalho (quanto mais proteolítico, mais intenso será o escurecimento); b) temperatura e tempo de exposição ao calor; c) umidade dos queijos, que pode estar relacionada com a presença de lactose residual e também à maturação mais acelerada; d) o alto teor de $\mathrm{NaCl}$ do queijo afeta cultivos Gal (+), o que causa uma lenta degradação da lactose e/ou galactose residuais, que pode reagir com o grupo amina, aumentando assim o escurecimento não enzimático (FURTADO, 2016).

O queijo de Coalho apresenta a propriedade tecnológica de manter as arestas definidas durante o aquecimento, sem que ocorra o derretimento. Derretimento é definido como a capacidade das partículas do queijo fluírem e formar uma fase uniformemente derretida, que é direcionada inicialmente pela evaporação da água e fluidificação da gordura (WANG; SUN, 2002). Para manter esta propriedade no queijo de Coalho, dois fatores são fundamentais:

- Manutenção do pH do queijo em valores próximos a 5,8 porque, em valores de $\mathrm{pH}$ próximos a 5,1, o queijo apresentará elevado grau de desmineralização, o que fará que derreta e se deforme quando submetido ao calor (MUNCK, 2004). $\mathrm{O}$ lactato presente no queijo quando seu pH está baixo solubiliza o cálcio coloidal - responsável pela ligação entre as micelas de paracaseína - na forma de lactato de cálcio, desmine- 
ralizando o paracaseinato bicálcico em paracaseinato monocálcico (KOSIKOWSKI, 1982), tornando a rede protéica mais frágil e assim mais propensa ao derretimento;

- Controle de proteólise do paracaseinato durante a estocagem dos queijos, uma vez que esta hidrólise também levará ao enfraquecimento da rede proteica, levando assim, ao derretimento (SOBRAL et al., 2007).

Os fatores que interferem no derretimento são: a) teor de gordura presente no queijo, sendo que quanto maior este, maior será o derretimento no momento do aquecimento; b) $\mathrm{pH}$, sendo que quanto mais alto, menor desmineralização e, portanto menor derretimento devido à maior estruturação da malha proteica; c) proteólise da massa, sendo que queijos mais úmidos tendem a apresentar proteólise mais acelerada e, portanto derretem mais (FURTADO, 2016). Quanto mais elevado o teor de $\mathrm{NaCl}$ do queijo, pior será o derretimento da massa (FURTADO, 2016) uma vez que o crescimento microbiano fica limitado e consequentemente a proteólise é inibida, além da menor quantidade de água disponível para essa reação.

O objetivo deste trabalho foi avaliar aspectos sensoriais de queijo de Coalho acidificado por adição de ácido lático e fermento mesofílico aromático sob diversos atributos por meio de Análise Descritiva Quantitativa.

\section{MATERIAL E MÉTODOS}

No experimento foram utilizadas parcelas subdivididas no tempo, com três tratamentos: queijos de Coalho fabricados com fermento mesofílico aromático $(1 / 8 \mathrm{da}$ dose recomendada) e sem ácido lático (CF); sem fermento e sem ácido lático (SF) e por acidificação direta (com $25 \mathrm{~mL}$ de ácido lático a $85 \%(\mathrm{v} / \mathrm{v})$ para cada $100 \mathrm{~L}$ de leite) e sem fermento (AL). Foram pesquisados cinco tempos de estocagem refrigerada (8, $15,30,60$ e 90 dias após a fabricação) e três repetições (fabricações). Os queijos de Coalho foram fabricados com 100 litros de leite em cada tratamento, proveniente do mesmo lote de leite pasteurizado LTLT $\left(65^{\circ} \mathrm{C} / 30 \mathrm{~min}\right)$. Nos tratamentos $\mathrm{CF}$ foi utilizada $1 / 8 \mathrm{da}$ dose recomendada do fermento mesofílico aromático (Lactococcus lactis subsp. lactis, Lactococcus lactis subsp cremoris, Lactococcus lactis subsp. lactis biovar diacetylactis e Leuconostoc mesenteroides subsp. cremoris), para evitar que o $\mathrm{pH}$ do queijo abaixasse e provocasse derretimento no queijo. Foi utilizada a tecnologia apresentada na Figura 1, descrita por Machado et al. (2011), sendo que a temperatura de aquecimento da massa foi de $42{ }^{\circ} \mathrm{C}$ para o queijo fabricado com fermento (CF) e de $50{ }^{\circ} \mathrm{C}$ para os queijos sem fermento (SF e AL).

\section{Recrutamento dos provadores}

Doze indivíduos dentre os pesquisadores e funcionários da Empresa de Pesquisa Agropecuária de Minas Gerais (EPAMIG) Instituto de Laticínios Cândido Tostes (ILCT) foram recrutados. Os seguintes critérios foram utilizados para seleção: ser consumidor de queijo Coalho e ter sido selecionado anteriormente para participar em equipes de análise sensorial descritiva de outros produtos lácteos, nos quais os provadores passaram por testes de seleção quanto a sua acuidade sensorial normal (reconhecimento de aromas e gostos básicos).

\section{Desenvolvimento da terminologia descritiva}

Para determinação dos descritores foram utilizadas as três amostras a serem analisadas de queijo de Coalho fabricados no Núcleo Industrial da EPAMIG ILCT. Foi utilizado o método de Rede (MOSKOWITZ, 1983), na qual as três amostras foram apresentadas simultaneamente. O provador deveria 
agrupar as amostras aos pares e descrever as similaridades e as diferenças entre elas. Para auxiliar na descrição dos atributos, foram apresentadas as características do queijo de Coalho segundo o Regulamento Técnico de Identidade e Qualidade do Ministério da Agricultura, Pecuária e Abastecimento, a
Instrução Normativa $n^{\circ} 30$, de 26 de junho de 2001 (BRASIL, 2001). Após cada provador ter gerado seus próprios termos, foi realizada uma discussão em grupo, sob a supervisão de um líder, com o objetivo de agrupar termos semelhantes e eliminar aqueles que não eram percebidos pela maioria dos provadores.

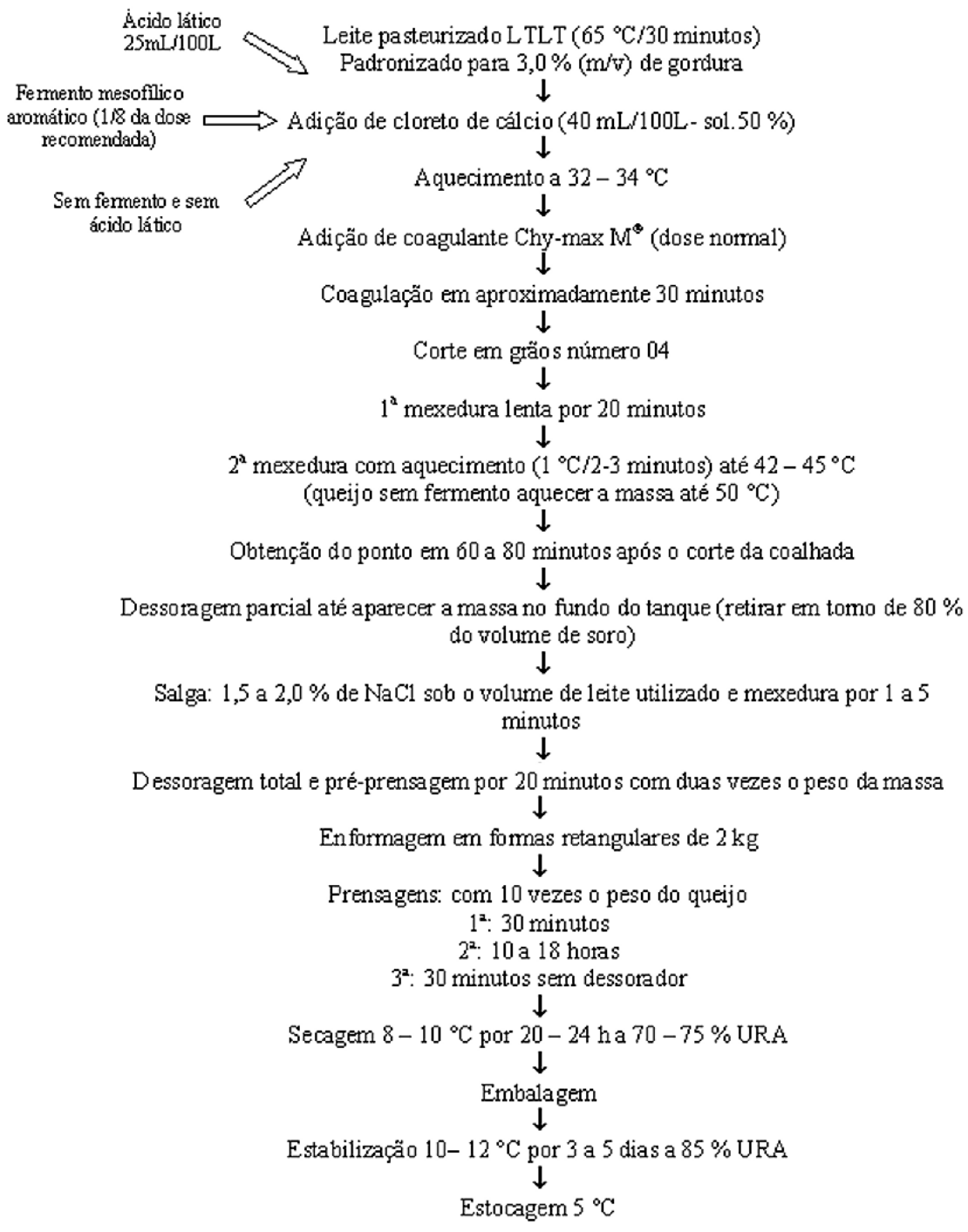

Figura 1 - Fluxograma da fabricação do queijo de Coalho com leite pasteurizado (MACHADO et al., 2011) 
Chegou-se ao consenso de 9 atributos: aspecto global, cor externa, odor característico, resistência ao derretimento, textura, ranger ao mastigar, gosto salgado, gosto ácido e sabor. Em seguida foram conduzidas 3 sessões de discussões em grupo com o objetivo de gerar definições e amostras de referência dos extremos da escala de intensidade. Outras sessões de avaliação das amostras foram realizadas para discussão em grupo, com um líder, para resultar na ficha final de avaliação das amostras. Os termos descritivos estão apresentados na Tabela 1.

\section{Seleção final da equipe de avaliadores}

As três amostras de queijo de Coalho foram avaliadas nessa etapa, no delineamento experimental em blocos completos casualizados com três repetições. Os provadores utilizaram a própria Ficha de Avaliação desenvolvida na etapa anterior. Foi permitido aos avaliadores consultar a lista de definições e as referências, durante sua análise.

Os resultados de cada provador para cada descritor avaliado foram analisados pela Análise de Variância, considerando como fontes de variação amostras e repetições. A equipe de provadores foi selecionada segundo metodologia proposta por Damasio; Costell (1991), de acordo com o bom poder discriminativo ( $\mathrm{p}_{\text {amostra }}<0,30$ ); consenso com os demais membros do grupo e reprodutibilidade nos julgamentos

$$
\left(\mathrm{p}_{\text {repetição }}>0,05\right) \text {. }
$$

\section{Avaliação das Amostras}

Os queijos foram submetidos à análise sensorial em todos os tempos de estocagem refrigerada descritos anteriormente para avaliação dos seguintes atributos: aspecto global, cor externa, odor característico, resistência ao derretimento, textura, ranger ao mastigar, gosto salgado, gosto ácido e sabor, utilizando-se de escala não-estruturada, seguindo a Análise Descritiva Quantitativa (ADQ) (STONE et al., 1974).

Os julgadores receberam as amostras em cabines individuais. As amostras foram codificadas com números de três dígitos aleatórios para serem apresentadas. O traço vertical, na ficha de resposta referente à nota de cada julgador, foi transformado em escore, medido em $\mathrm{cm}$, do comprimento da linha assinalada na ficha de resposta (escala de $15 \mathrm{~cm}$ ou 15 pontos).

O queijo foi oferecido aos provadores em cubos de $3 \times 3 \times 3 \mathrm{~cm}$, fritos três a três, com $6 \mathrm{~mL}$ de manteiga de garrafa, em fogo brando, por 4 a 5 minutos, dourando os quatro lados do queijo por igual.

\section{Análise estatística}

As respostas dos provadores foram transformadas em valores numéricos, para análise de variância, seguida pelo teste de Tukey $(\mathrm{p}<0,05)$, por programa estatístico apropriado SISVAR (FERREIRA, 2008).

\section{RESULTADOS E DISCUSSÃO}

\section{Aspecto global}

O aspecto global foi o primeiro atributo avaliado pelos provadores treinados, sendo este um parâmetro em que as diversas características do queijo são avaliadas em conjunto no momento em que o queijo é apresentado ao julgador. Numa escala de $15 \mathrm{~cm}$ variando entre os termos atípico e típico, todas as notas conferidas pelos julgadores em todos os tempos e tratamentos foram maiores que 11, aproximando-se do termo típico, que é o desejável para o queijo de Coalho. A análise de variância demonstrou que os tratamentos não diferiram entre si $(\mathrm{p}=0,3940)$, bem como não houve interação entre tempo de estocagem refrigerada e tratamentos 
$(\mathrm{p}=0,7320)$. As médias para os tratamentos $\mathrm{AL}, \mathrm{CF}$ e SF foram, respectivamente, 12,2; 12,4 e 12,6. Dessa forma, o queijo de Coalho produzido com ácido lático foi semelhante em relação ao seu aspecto global aos outros dois queijos em cada tempo de análise.
Porém, o tempo foi um fator relevante para a avaliação do aspecto global dos queijos $(\mathrm{p}=0,0000)$, sendo que as melhores notas foram encontradas no início da estocagem do produto, conforme pode ser visualizado na Figura 2. Este comportamento está relacionado

Tabela 1 - Lista dos termos descritivos e respectivas referências para o queijo de Coalho

\begin{tabular}{|c|c|c|}
\hline Atributo & Definição & Referências \\
\hline Aspecto global & $\begin{array}{l}\text { Aparência do produto revelada } \\
\text { na primeira impressão }\end{array}$ & $\begin{array}{l}\text { Típico: queijo de Coalho com } 7 \text { dias de } \\
\text { fabricação } \\
\text { Atípico: queijo de Coalho com } 90 \text { dias } \\
\text { de fabricação }\end{array}$ \\
\hline Cor externa & $\begin{array}{l}\text { Cor amarronzada } \\
\text { característica do queijo frito }\end{array}$ & $\begin{array}{l}\text { Escura: cor marrom escura, queijo tostado } \\
\text { Clara: Queijo Frescal }\end{array}$ \\
\hline Odor característico & Odor pouco ácido & $\begin{array}{l}\text { Muito pronunciado: odor ácido de iogurte } \\
\text { natural } \\
\text { Ausente: nenhum }\end{array}$ \\
\hline $\begin{array}{l}\text { Resistência } \\
\text { ao derretimento }\end{array}$ & $\begin{array}{l}\text { Arestas definidas nos cubos } \\
\text { de queijos fritos }\end{array}$ & $\begin{array}{l}\text { Definida: arestas do cubo com quinas } \\
\text { formando } 90^{\circ} \\
\text { Indefinida: queijo sem arestas, arestas } \\
\text { arredondadas }\end{array}$ \\
\hline Textura & $\begin{array}{l}\text { Presença de olhaduras } \\
\text { mecânicas na massa }\end{array}$ & $\begin{array}{l}\text { Aberta: Olhaduras mecânicas aparentes } \\
\text { como no queijo Frescal } \\
\text { Fechada: ausência de olhaduras }\end{array}$ \\
\hline Ranger ao mastigar & Queijo "borrachento" & $\begin{array}{l}\text { Intenso: queijo range nos dentes quando } \\
\text { mastigado, firme ( } 42 \% \text { de umidade) } \\
\text { Ausente: queijo mole, fácil de mastigar } \\
\text { (Queijo Frescal) }\end{array}$ \\
\hline Gosto salgado & $\begin{array}{l}\text { Sensação do gosto básico } \\
\text { provocado pelo sal }\end{array}$ & $\begin{array}{l}\text { Forte: queijo gorgonzola }(3,5 \% \text { de sal }) \\
\text { Fraco: queijo Frescal }(1,2 \% \text { sal })\end{array}$ \\
\hline Gosto ácido & $\begin{array}{l}\text { Gosto característico } \\
\text { da fermentação do leite }\end{array}$ & $\begin{array}{l}\text { Muito pronunciado: iogurte natural } \\
\text { Ausente: nenhum }\end{array}$ \\
\hline Sabor & $\begin{array}{l}\text { Sabor característico de } \\
\text { queijo de Coalho }\end{array}$ & $\begin{array}{l}\text { Muito pronunciado: queijo Coalho } \\
\text { fabricado com dose normal de fermento } \\
\text { mesofílico aromático } \\
\text { Ausente: nenhum }\end{array}$ \\
\hline
\end{tabular}


com a deterioração dos atributos gerais do queijo devido aos processos bioquímicos ocorridos no produto durante o tempo que se manteve estocado (MACHADO et al., 2011). Assim, recomenda-se que o queijo de Coalho seja consumido o mais fresco possível para preservar suas características gerais, sendo que o período de validade de 3 a 4 meses normalmente encontrado nos queijos de Coalho vendidos no mercado pode ser considerado muito extenso.

\section{Cor externa}

A variação da cor para o queijo de Coalho frito em manteiga de garrafa foi do 0 (queijo claro) ao 15 (queijo escuro), sendo o ideal para este tipo de queijo devendo estar mais próximo do termo escuro, devido a reação de Maillard que é característica nesse queijo. O valor de 15 nessa escala é uma cor escura extrema que não é desejável no produto. Como as notas médias dos julgadores treinados estiveram acima de 10 para todos os tratamentos e tempos, estas notas foram próximas ao esperado para o queijo de Coalho.

A análise de variância mostrou que os tratamentos não diferiram entre $\mathrm{si}(\mathrm{p}=0,3580)$, bem como não houve interação entre tempo e tratamento para a cor dos queijos estudados $(\mathrm{p}=0,5350)$. As médias para os tratamentos AL, CF e SF foram, respectivamente, de 11,0; 11,1 e 10,8 . Porém o tempo foi significante para este atributo $(p=0,0320)$, o que pode ser visto na Figura 2. Os queijos obtiveram notas menores no final da estocagem aproximandose do termo "clara", possivelmente pela degradação da lactose durante o período estudado e assim diminuindo a ocorrência da reação de Maillard, apesar da proteólise mais avançada, durante a fritura dos queijos. Essa redução no teor residual de lactose era esperada devido à ação de bactérias láticas (contaminantes ou adicionadas, no caso do tratamento "com fermento") que ao fermentar a lactose a transformam em ácido lático, diminuindo o pH dos queijos (AYYASH; SHAH, 2011), o que pode ser verificado nesse experimento, nos dados publicados (MACHADO et al., 2011).

\section{Odor característico}

Outra característica avaliada nos queijos foi o odor característico dos mesmos, sendo avaliado de ausente (0) a muito pronunciado (15), os queijos de Coalho em todos os tratamentos e tempos receberam notas médias maiores que 10. Conforme o Regulamento Técnico de Identidade e Qualidade do Queijo de Coalho (BRASIL, 2001) este produto deve apresentar odor ligeiramente ácido lembrando massa coagulada, podendo ser considerado como pronunciado.

A análise de variância mostrou que não houve diferença entre os odores dos queijos de Coalho produzidos com ácido lático, com fermento e sem adição de fermento $(p=0,9740)$ para nenhum tempo de estocagem refrigerada $(\mathrm{p}=0,4620)$, assim como o tempo também não foi significativo $(\mathrm{p}=0,1060)$ para este atributo nos queijos de Coalho. As médias para os tratamentos $\mathrm{AL}, \mathrm{CF}$ e $\mathrm{SF}$ foram, respectivamente, de 11,2; 11,1 e 11,2 e a média geral dos tempos foi de 11,2. Embora tenha sido utilizado fermento mesofílico aromático em um dos tratamentos $(\mathrm{CF})$, o odor não foi diferenciado devido à baixa dosagem empregada (1/8 da dose normal).

\section{Resistência ao derretimento}

A resistência ao derretimento é uma das características funcionais do queijo de Coalho. $O$ consumidor espera que este queijo, quando submetido ao calor, não sofra deformação significativa de suas arestas e de sua forma (SOBRAL et al., 2007). Esse atributo passa a ser mais relevante se o queijo de Coalho for assado em espetos, maneira pela qual é 
muitas vezes consumido em diversas partes do país. As arestas dos queijos de Coalho foram avaliadas entre as denominações indefinidas (0) a definidas (15) que é o ideal esperado para este tipo de queijo, sendo que a menor nota média para este atributo foi 10,7 para o queijo adicionado de ácido lático com 60 dias de estocagem refrigerada. Como para o queijo de Coalho é esperado que não ocorra o derretimento (arestas definidas), as notas altas dadas pelos julgadores mostraram que esta característica foi de uma maneira geral atendida em todos os tratamentos.

Para este parâmetro também não foram encontradas diferenças significativas, sejam elas relacionadas aos efeitos principais de tempo $(\mathrm{p}=0,0750)$ e tratamento $(\mathrm{p}=0,1350)$, ou à interação entre o tempo de estocagem e os tratamentos estudados $(\mathrm{p}=0,1930)$. As médias para os tratamentos AL, CF e SF foram, respectivamente, de 11,5; 11,9 e 12,0 e a média geral dos tempos foi de 11,8. Embora queijos fabricados com acidificação direta derretam mais devido ao seu menor teor de cálcio (McMAHON et al., 2005), isso não foi observado nesse trabalho. Foi verificado um aumento nos índices de proteólise ao longo do tempo (MACHADO et al., 2011), que interfere diretamente no derretimento, pelo enfraquecimento da rede proteica (McSWEENEY, 2004), no entanto, não houve influência na resistência ao derretimento.

\section{Textura}

A textura do queijo está relacionada com a presença de olhaduras no produto, sejam elas mecânicas ou oriundas de gases produzidos por processos bioquímicos de microrganismos. Este atributo foi avaliado entre os termos fechada (0) e aberta (15) e devido à presença de algumas olhaduras mecânicas que são esperadas no queijo submetido a salga na massa, esperava-se as notas intermediárias recebidas para o queijo de Coalho em relação a esse atributo, entre 8,0 e 10,3 .

A análise de variância mostrou que houve diferença significativa da textura dos queijos entre os tratamentos $(p=0,0120)$ (Tabela 2), enquanto o tempo de estocagem $(\mathrm{p}=0,5470)$ e a interação entre tempo e tratamento ( $p$ $=0,4950)$ não foram significativamente diferentes para este atributo sensorial. A textura dos queijos de Coalho produzidos com ácido lático foi mais aberta que a do produzido com fermento. Uma vez que as olhaduras observadas não foram oriundas de fermentação devido à baixa dosagem utilizada, mas sim mecânicas, este fato pode ser explicado por diferenças na prensagem dos queijos e também devido à salga na massa após a dessoragem parcial (FURTADO, 1991).

Tabela 2 - Notas médias dos avaliadores para a textura dos queijos de Coalho durante seu tempo de estocagem refrigerada*

\section{Queijo AL Queijo CF Queijo SF}

$9,6^{\mathrm{A}} 8,5^{\mathrm{B}} \quad 9,4^{\mathrm{AB}}$
* Letras iguais indicam valores semelhantes pelo teste
de Tukey ao nível de 5\% de probabilidade.

\section{Ranger ao mastigar}

O queijo de Coalho apresenta tradicionalmente um ranger ao mastigar que é característico deste produto. Sua avaliação sensorial foi determinada entre os termos ausente (0) a intenso (15). Um ranger muito intenso pode ser considerado um defeito, pois o queijo com essa característica seria rejeitado pelo consumidor.

Para este atributo a análise de variância mostrou que os tratamentos foram semelhantes entre si $(p=0,0510)$, isto é, os queijos de Coalho produzidos com ácido lático, com fermento e sem fermento apresentaram um ranger ao mastigar semelhantes (considerando 
os tratamentos como efeitos principais). Não houve interação significativa $(\mathrm{p}=0,9020)$ entre tempo de estocagem e tratamentos, o que mostra que para cada tempo de estocagem foram atribuídas notas semelhantes aos queijos quanto ao citado atributo sensorial. Porém, o tempo em que os queijos foram estocados foi relevante para influenciar as notas dos mesmos $(p=0,0000)$, sendo que estas foram diminuindo gradativamente à medida que os queijos foram ficando mais tempo estocados (Figura 2). Assim nota-se que com o tempo, o queijo de Coalho vai perdendo a sua característica de ranger ao ser mastigado e isto possivelmente se deve ao fato dos queijos apresentarem uma proteólise (MACHADO et al., 2011) que vai se intensificando com o passar do tempo, tornando a malha proteica mais frágil e menos resistente.

\section{Gosto salgado}

O gosto salgado dos queijos de Coalho, importante atributo sensorial por ser um queijo de origem nordestina onde a preferência por produtos mais salgados é reconhecida, foi avaliada pelo grupo de provadores treinados entre os termos fraco $(0)$ e forte (15), sendo 8,1 e 10,4 respectivamente a menor e maior nota conferida a um dos queijos estudados. $\mathrm{O}$ valor de 15 nesse atributo seria um queijo extremamente salgado, o que dificultaria seu consumo.

Os tratamentos não foram diferentes entre si $(p=0,1180)$ com relação ao gosto salgado e não houve interação entre tempo de estocagem e tratamento $(\mathrm{p}=0,2650)$. Porém, o tempo de estocagem alterou a percepção sensorial dos provadores em relação ao gosto salgado $(p=0,0000)$, uma vez que o teor de $\mathrm{NaCl}$ se manteve constante e os queijos foram conservados embalados na câmara fria, não ocorrendo assim perda de umidade e consequente concentração do extrato seco. Observou-se que nos tempos 8 e 15 dias de estocagem, as notas foram semelhantes e maiores que as obtidas nos tempos 30, $60 \mathrm{e}$ 90 dias. Assim, como as notas para o gosto salgado diminuíram com o tempo, a percepção para essa característica diminuiu, tornandose menos importante sensorialmente que os demais gostos e atributos que foram gerados no queijo durante os processos bioquímicos que ocorreram durante a estocagem, como o gosto amargo, perceptível ou detectável a partir de 30 dias de fabricação.

\section{Gosto ácido}

O gosto ácido é um interessante atributo a ser pesquisado, uma vez que no queijo de Coalho artesanal produzido no Nordeste, apesar das diferenças regionais locais, tradicionalmente é feito com leite cru e sem adição de fermento. A acidez desenvolvida neste tipo de queijo é, assim, oriunda da fermentação produzida pelas bactérias láticas endógenas do leite e contaminantes. O gosto ácido passa a ser então característico deste produto e o uso de leite pasteurizado, a adição ou não de fermento, e outros parâmetros de fabricação, podem levar a modificações dessa característica.

A avaliação foi feita entre os termos ausente (0) e muito pronunciado (15), e a nota média geral foi 2,5 , próxima a ausente. O tempo foi relevante na percepção do gosto ácido $(\mathrm{p}=0,0000)$, que foi aumentando com o tempo de estocagem (Figura 3). Com 60 e 90 dias de estocagem refrigerada foram atribuídas as maiores notas para este atributo, resultado da produção de ácido ao longo da estocagem pelas bactérias do fermento e contaminantes, o que pode ser verificado pela redução do $\mathrm{pH}$ ao longo do tempo de estocagem refrigerada (MACHADO et al., 2011). Não houve interação entre tempo e tratamento dos queijos analisados $(\mathrm{p}=0,7750)$ e os tratamentos (efeito principal) foram semelhantes entre si $(p=0,1740)$. 
Sabor

O sabor dos queijos de Coalho foi avaliado pelos julgadores, sendo para esta característica atribuída os seguintes termos de avaliação: ausente (0) a muito pronunciado (15); as notas ficaram mais próximas do termo muito pronunciado (média geral 9,8). O sabor é fundamental para a aceitação sensorial do produto e notas altas não estão exatamente relacionadas com um sabor melhor, uma vez que o termo utilizado para esta característica não foi sabor característico, mas somente sabor.

A análise de variância mostrou que não houve interação entre tempo e tratamento $(p=0,7670)$ e os tratamentos foram semelhantes entre si com relação ao sabor $(\mathrm{p}=0,8750)$. As médias para os tratamentos AL, CF e SF foram, respectivamente, de 9,8; 9,8 e 9,7. O tempo foi o fator significativamente $(p=0,0010)$ influenciador das notas atribuídas pelos julgadores ao sabor dos queijos de
Coalho (Figura 3). As notas maiores foram atribuídas no início e no final da estocagem refrigerada. Nos primeiros dias de estocagem o sabor estava relacionado com atributos sensoriais agradáveis intrínsecos ao queijo e avaliados globalmente pelos julgadores. Porém, no final da estocagem o sabor estava muito pronunciado, e o gosto amargo, embora não relacionado na ficha de avaliação, foi o que mais contou para aumentar novamente as notas para o sabor dos queijos de Coalho.

Os queijos de Coalho adicionados de fermento apresentaram gosto amargo mais pronunciado, que começou a ser notado com 60 dias de fabricação. Conforme Sousa et al. (2001) o gosto amargo em queijos é devido principalmente a peptídeos hidrofóbicos liberados pela proteólise das caseínas, sendo a quimosina residual a enzima mais importante neste processo. Os queijos fabricados sem fermento e com ácido lático foram aquecidos até $50{ }^{\circ} \mathrm{C}$ durante a fabricação, o que pode
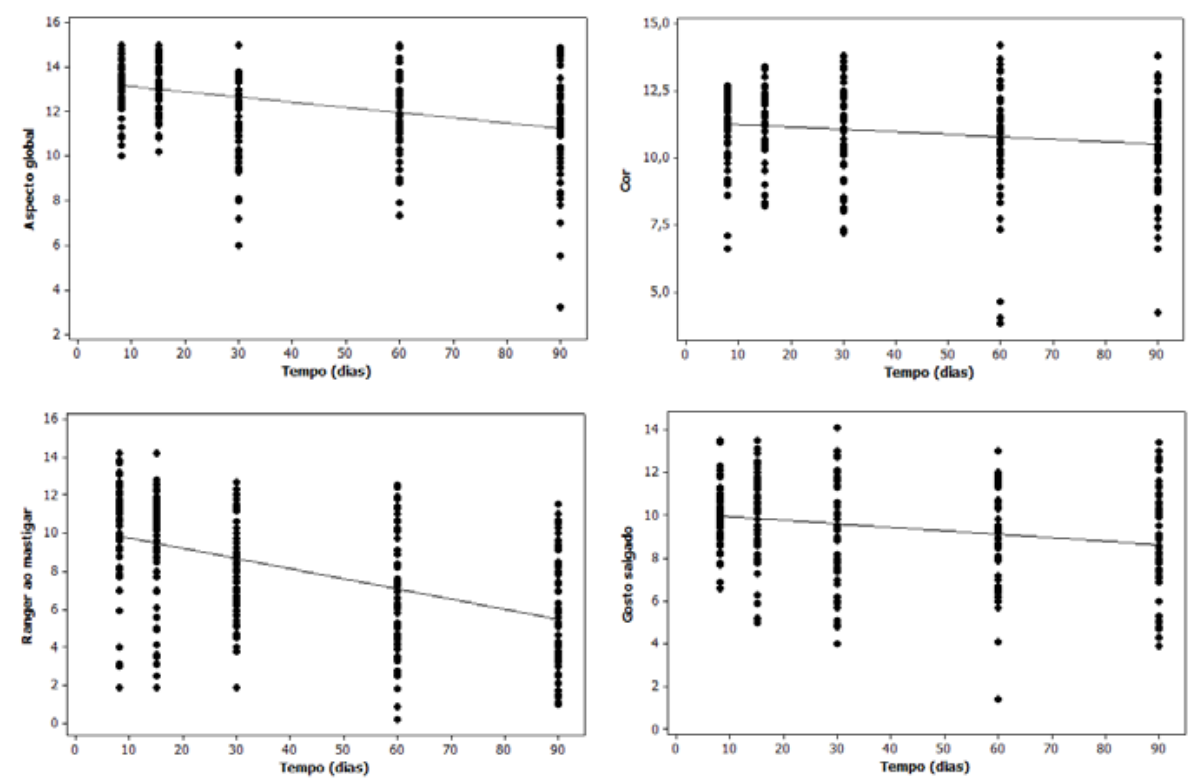

Figura 2 - Atributos sensoriais (Aspecto global, cor, ranger ao mastigar, gosto salgado) avaliados no queijo de Coalho ao longo do tempo de estocagem refrigerada 
ter levado a uma desnaturação parcial do coagulante. Os peptídeos de média e baixa massa molecular gerados da proteólise contribuem para um sabor agradável em muitas variedades de queijos, no entanto, esses últimos oriundos do coagulante são hidrofóbicos e apresentam gosto amargo (McSWEENEY, 2004).

A Figura 4 apresenta os resultados médios dos queijos de Coalho aos 30 dias de estocagem refrigerada, em que as características sensoriais são próximas. Observase que ao longo do tempo (60 dias), essas características são alteradas, com redução das notas como para o atributo ranger ao mastigar, o que é indesejável, por isso, recomendase o consumo de queijo de Coalho o mais rápido possível para que ele conserve suas características funcionais intactas.

\section{CONCLUSÕES}

A Análise Descritiva Quantitativa mostrou que para a maior parte dos atributos o tempo é o único parâmetro realmente significativo nos julgamentos dos queijos de Coalho com diferentes tratamentos. Os queijos são semelhantes entre si e somente para o atributo textura houve diferenciação entre os tratamentos, com melhor escore no queijo fabricado com ácido lático.

\section{AGRADECIMENTOS}

À Fundação de Amparo à Pesquisa do Estado de Minas Gerais - FAPEMIG pelo financiamento do projeto CVZ-APQ-00083/08 e pelas bolsas concedidas.
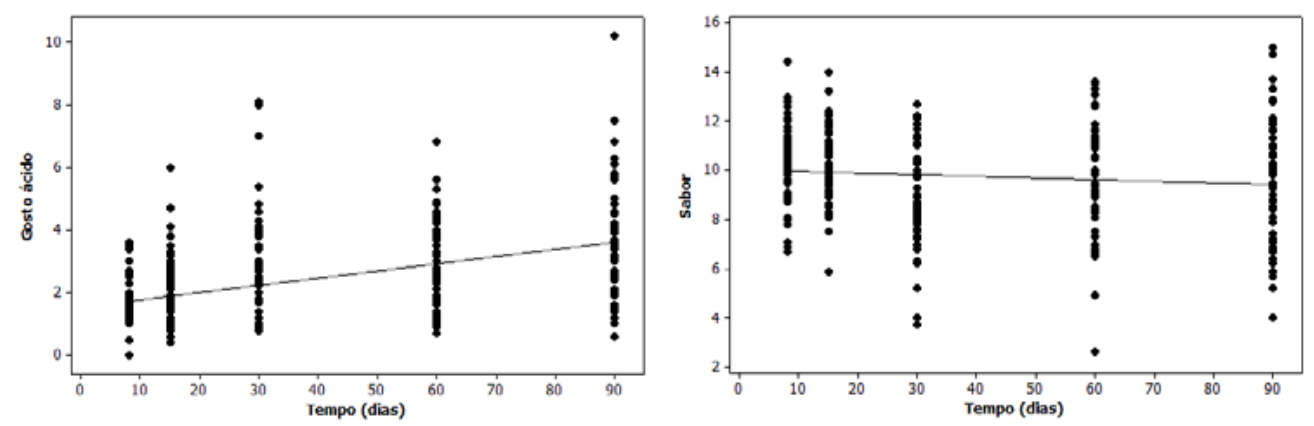

Figura 3 - Atributos sensoriais (gosto ácido e sabor) avaliados no queijo de Coalho ao longo do tempo de estocagem refrigerada
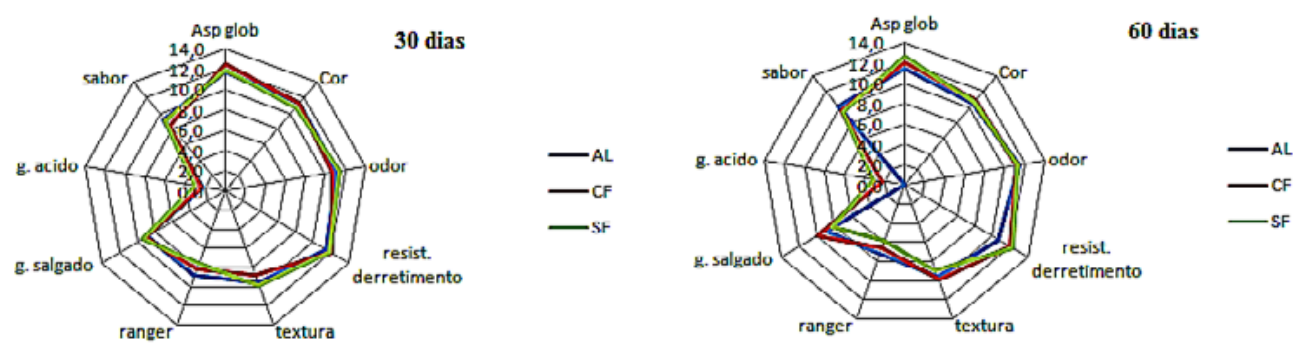

Figura 4 - Gráfico Aranha da Análise Descritiva Quantitativa do queijo de Coalho aos 30 e 60 dias de estocagem refrigerada 


\section{REFERÊNCIAS}

AYYASH, M. M.; SHAH, N. P. Effect of partial substitution of $\mathrm{NaCl}$ with $\mathrm{KCl}$ on proteolysis of Halloumi cheese. Journal of Food Science, v. 76, n. 1, p. 31-37, 2011.

BEZERRA, T. K. A. et al. Proteolysis in goat "Coalho" cheese supplemented with probiotic lactic acid bacteria. Food Chemistry, v. 196, p. 359-366, 2016.

BRASIL. Ministério da Agricultura e do Abastecimento. Instrução Normativa $n^{\circ} 30$, de 26 de junho de 2000. Regulamento Técnico de Identidade e Qualidade de Manteiga da Terra ou Manteiga de Garrafa, Queijo de Coalho e Queijo de Manteiga. Diário Oficial da República Federativa do Brasil: seção 1, Brasília, DF, n. 136, p. 13, 16 jul. 2001.

DAMASIO, M. H.; COSTEll, E. Análisis sensorial descriptivo: generación de descriptores y selección de catadores. Revista Agroquímica de Tecnología de Alimentos, v. 31, n. 2, p. 165-78, 1991.

FERREIRA, D. F. SISVAR: Um programa para análises e ensino de estatística. Revista Científica Symposium, v. 6, n. 2, p. 36-41, 2008.

FURTADO, M. M. A Arte e a Ciência do Queijo. São Paulo: Globo, 1991. 297p.

FURTADO, M. M. Mussarela - Fabricação \& Funcionalidade. São Paulo: Setembro Editora, 2016. 245p.

KOSIKOWSKI, F. Cheese and Fermented Milk Foods. New York: Elsevier, 1982. 711 p.

MACHADO, G. M. M. et al. Aspectos físicoquímicos de queijo de Coalho fabricado com o uso de ácido lático. Alimentos e Nutrição, v. 22, n. 3, p. 421-428, 2011.
McMAHON, D. J.; PAULSON, B.; OBERG, C. J. Influence of calcium, $\mathrm{pH}$, and moisture on protein matrix structure and functionality in direct-acidified nonfat mozzarella cheese. Journal of Dairy Science, v. 88, n. 11, p. 3754-3763, 2005.

McSWEENEY, P. L. H. Biochemistry of cheese ripening. International Journal of Dairy Technology, v. 27, n. 2/3 p. 127-144, 2004.

MOSKOWITZ, H. R. Product Testing and Sensory Evaluation of Foods: Marketing and R \& D Approacher. Westport: Food and Nutrition Press, 1983. 605 p.

MUNCK, A. V. Queijo de Coalho: Princípios básicos da fabricação. Revista do Instituto de Laticínios Cândido Tostes, v. 59, n. 339, p. 13-15, 2004.

SOBRAL, D.; PAULA, J. C. J.; SILVA, P. H. F. Queijo de Coalho: Características e tecnologia. Informe Agropecuário, Agroindústria: Leite e Derivados, v. 28, n. 238, p. 57-62, 2007.

SOUSA, M. J.; ARDO, Y.; McSWEENEY, P. L. H. Advances in the study of proteolysis during cheese ripening. International Dairy Journal, v. 11, p. 327-345, 2001.

STONE, J. R. et al. Sensory evaluation by quantitative descriptive analysis. Food Technology, v. 28, n. 11, p. 24-34, 1974.

TAMANNA, N.; MAHMOOD, N. Food processing and Maillard reaction products: Effect on human health and nutrition. International Journal of Food Science, v. 2015, Article ID 526762, 6 p., 2015.

WANG, H. H.; SUN, D. W. Melting characteristics of cheese: analysis of effects of cooking conditions using computer vision technology. Journal of Food Engineering, v. 51 , p. $305-310,2002$. 